\title{
A CONSTITUIÇÃO DO SUJEITO NA ATIVIDADE
} ESTÉTICA DA DANÇA DO VENTRE CONSTITUTION OF SUBJECTIVITY IN THE AESTHETIC ACTIVITY OF BELLY DANCE

\author{
Alice Casanova dos Reis \\ Universidade de São Paulo, São Paulo, Brasil \\ Andréa Vieira Zanella \\ Universidade Federal de Santa Catarina, Florianópolis, Brasil
}

\section{RESUMO}

O texto apresenta uma pesquisa cujo objetivo foi compreender de que modo a atividade estética da dança do ventre se concretiza e sua mediação na constituição do sujeito. Partindo de uma perspectiva histórico-cultural, a análise da entrevista com uma bailarina revelou diversas relações estéticas mediando a realização da dança: da bailarina com a técnica, com o corpo, com a música, com o público, com o sagrado, com o feminino. Compreendeu-se que nessas relações se engendram diferentes possibilidades de subjetivação, que convergem à constituição do sujeito como devir estético na dança do ventre.

Palavras-chave: subjetividade; atividade estética; dança do ventre.

\begin{abstract}
This text presents a research that aims to understand in which way the aesthetic activity of belly dance is concretized, and its mediation on the constitution of subjectivity. From a historical-cultural perspective, the analysis of an interview with a belly dancer revealed many aesthetic relations intervening the dance performance: how the belly dancer relates to the technique, to her body, to the music, to the public, to the sacred, to feminine conceptions. The text perceives that different possibilities of subjectivation are engendered through these relations, and converge in the constitution of the dancer as the aesthetic subject of the belly dance.
\end{abstract}

Keywords: subjectivity, aesthetic activity, belly dance.

No presente artigo são apresentados os resultados de uma investigação que enfocou a dança do ventre com o objetivo de compreender de que modo essa atividade estética se concretiza e sua mediação na constituição do sujeito. Partindo das contribuições teóricas de Bakhtin (1993, 2003a) e Vygostki (1990, 1999), delineou-se a arquitetônica conceitual sobre a qual se erigiu a análise empreendida e cujos pontos principais agora apresentamos.

A dança do ventre é uma prática social historicamente constituída a partir de diferentes significados, consoantes com as características culturais do contexto em que se inseria (Bencardini, 2002; Hanna, 1999). No processo de seu desenvolvimento, perdeu sua função sagrada original e paulatinamente tornou-se parte do legado cultural árabe e uma forma de expressão artística, significados que predominaram em sua apropriação pelo Ocidente. No Brasil, ela é apresentada sobretudo em restaurantes árabes, além de ganhar cada vez mais espaço nos teatros, a partir de seu desenvolvimento em escolas de dança especializadas ${ }^{1}$.

Na reconstrução desse percurso, buscou-se problematizar a questão de gênero que vem permeando essa atividade associada ao feminino. A partir do diálogo com algumas feministas (Butler, 2003; De Lauretis, 2003; Nicholson, 2000; Scott, 1990), partiu-se de uma visão crítica de gênero, concebido como algo que não está propriamente no corpo, mas no modo como ele é percebido a partir de significações socialmente produzidas em relações de poder entre homens e mulheres. Essa noção de gênero, portanto, foi subjacente à análise, possibilitando desnaturalizar o feminino, para apreender seu caráter construtivo e o modo específico dessa construção na dança do ventre.

Toda dança é enformação estética do corpo. $\mathrm{Na}$ dança, o corpo transfigura-se em formas (Dantas, 1999) 
- formas de círculos, oitos e ondas, como acontece na dança do ventre - e, à medida que enforma o movimento, é por ele transformado. Nesse processo, o sujeito que dança se transforma, e a bailarina se torna a dança, ideia essa concebida em sintonia com uma visão monista que busca superar dialeticamente o dualismo cartesiano (Bakhtin, 2004; Vygostki, 1991), considerando que "O eu não é uma instância incorpórea, abstrata e imaterial que habita ou possui um corpo. $\mathrm{O}$ sujeito não tem um corpo. O sujeito é corpo" (Reis, 2007, p. 41).

Além do corpo, outra categoria central para compreender o processo de constituição do sujeito na dança investigada foi a alteridade, ou seja, a dimensão da relação semioticamente mediada com um outro, por meio da qual o eu se constitui. Essa dimensão está presente na própria concepção triádica da atividade estética, desenvolvida por Bakhtin (2003a), segundo a qual a obra de arte materializa uma forma de inter-relação entre seu criador e contemplador. Na dança em geral, essa relação seria triangulada entre a coreógrafa (criadora da dança), a bailarina (intérprete da dança, personagem criada) e o público espectador (contemplador da dança). Com exceção da obra, concreta por natureza, os demais lugares podem ser pensados de um modo abstrato, como princípios constitutivos da atividade estética. Assim, o autor é o princípio ativo na criação do objeto estético, a diretriz responsável por seu acabamento plástico, operando desde uma posição exotópica, ou seja, desde uma posição exterior ao personagem, de onde possui um excedente de visão, que lhe permite abarcá-lo enquanto totalidade (Bakhtin, 2003a). O contemplador, por sua vez, está na posição de recepção estética da obra e, uma vez que o sentido dessa não está dado, mas é completado por seu olhar, o espectador participa na atividade estética como cocriador.

Um dos desafios da pesquisa foi compreender a complexidade dessa relação na atividade estética investigada, especialmente quando a dança do ventre não é previamente coreografada, mas concebida no momento mesmo de sua apresentação, por meio da improvisação da bailarina. Nesse caso, propôs-se pensar em um desdobramento do sujeito que, criando a dança, recria-se como outro. Esse fenômeno pode estar presente em diferentes gêneros de dança, como, por exemplo, na dança contemporânea, quando a bailarina é criadora e intérprete ${ }^{2}$.

\section{O caminho trilhado}

A aproximação empírica ao objeto de pesquisa seguiu por duas vias: pesquisa documental e entrevista. A primeira consistiu no levantamento de documentos de domínio público (Spink, 2000), sistematizando informações a partir de fontes diversas (fitas VHS e
DVD's de apresentações de dança do ventre de diversas bailarinas, além de uma variedade de material coletado na Internet, tais como textos, fotos, imagens, vídeos disponibilizados em sites de bailarinas e no YouTube). Esse material, em sua maioria imagético, visou complementar a pesquisa, proporcionando visibilidade ao fenômeno investigado (Peixoto, 1998).

A segunda e mais importante via de investigação consistiu na entrevista realizada com uma bailarina brasileira profissional e professora de dança do ventre, aqui designada pelo nome fictício de Jalila, que contava com 23 anos de idade à época da realização da pesquisa. Após 10 anos no balé clássico, Jalila estava praticando a dança do ventre há oito anos, apresentavase em restaurantes árabes e festivais de dança, tendo obtido o $1^{\circ}$ lugar em um desses festivais e conquistado reconhecimento nacional pela qualidade artística de seu trabalho. A entrevista foi realizada na casa da bailarina e durou cerca de três horas. Uma vez que à pesquisa interessava a dança enquanto atividade-tipo, a participação de uma bailarina se revelou suficiente, pois, ainda que um exemplo único, trazia consigo também o que essa atividade tem de generalizável (Sobral, 2005).

A entrevista consistiu em um encontro reflexivo (Szymanski, 2000) que enfocou múltiplos aspectos da vivência da dança do ventre pela bailarina. Depois de transcrita, procedeu-se à análise do discurso, compreendendo-se a tarefa analítica como momento de interpretação construído a partir da correlação de um texto com outros textos (Bakhtin, 2003b). Assim, na inter-relação dialógica entre os enunciados da entrevistada, a escrita da pesquisadora e textos de referência teórica, produziu-se um conhecimento polifônico acerca da dança do ventre, entendendo-se que a polifonia do discurso caracteriza "a posição do autor como regente do grande coro de vozes que participam do processo dialógico" (Bezerra, 2005, p. 194).

A análise foi estruturada a partir de categorias que buscaram dar conta das múltiplas facetas que constituem essa atividade estética. As categorias foram estabelecidas a posteriori a partir da leitura em profundidade do material coletado, tendo sido consideradas como unidades temáticas de sentido, presentes na significação da dança do ventre pela bailarina e mediadoras do processo de constituição do sujeito naquela atividade.

\section{Relações estéticas e constituição do sujeito na dança do ventre}

A mediação das relações estéticas no processo de constituição do sujeito esteve presente de diferentes modos no discurso de Jalila, aparecendo seja na narrativa de situações concretas por ela vividas, seja em 
seus pensamentos e sentimentos associados à dança do ventre. Relação estética concerne a um modo de relação sensível e criativo, no qual se destaca a forma significativa do objeto para o sujeito concreto que com ele se relaciona esteticamente (Sánchez-Vázquez, 1999). Foram analisadas as seguintes relações estéticas: da bailarina com a técnica, com seu próprio corpo, com a música, com o público, e com alguns aspectos históricos da dança do ventre (o sagrado e o feminino). Vejamos cada uma delas.

\section{Processo de criação e técnica da dança}

Os diferentes gêneros artísticos de dança possuem cada qual sua técnica própria, ou seja, possuem um determinado modo de fazer, que inclui elementos como o código da dança (repertório de passos) e certas regras para seu uso, delimitando de certo modo a atividade do artista. No entanto, mais do que seu aspecto restritivo, destacou-se no discurso de Jalila o caráter instrumental da técnica no processo de criação da dança do ventre, como se vê no trecho a seguir:

A gente recebe as ferramentas, como se fosse um pincel, assim, o pincel e as tintas e o quadro, aí o que tu vais pintar, tu que pinta. Não é uma coisa como o balé clássico, por exemplo, que é como se fosse uma tela já com o risco que você só vai pintar, só vai colorir, preencher, né. E com a dança do ventre eu sinto que eu tenho uma liberdade muito maior, a tela está branca, eu pego a tinta e pinto como eu quiser, do jeito que eu achar que fica melhor, como eu me sinto na hora, porque eu trabalho muito improviso. Eu não gosto muito de coreografar, porque eu acho que isso corta um pouco, tira um pouco a vida sabe da tua dança, porque dançar é estar vivo naquele momento e botar pra fora o que está sentindo.

A relação de Jalila com a técnica muda em função da dança considerada. Em um balé de repertório, por exemplo, preenchendo como intérprete um lugar previamente delineado pelo coreógrafo, a bailarina-obra objetiva a criação de um outro, subjetivando-se como objeto estético nessa relação. Já na dança do ventre, ela se sente livre pra criar, utilizando o improviso e fazendo da dança uma forma de objetivar seus sentimentos. Aqui a posição ocupada por ela na atividade estética é outra: ela é ao mesmo tempo autora e atora da dança, criada enquanto é por ela protagonizada. Nessa posição, relaciona-se de modo criativo com a técnica, conforme explica:

Eu sinto que a dança do ventre te permite criar muitas coisas, tu não precisas ficar tão limitada naqueles movimentos $\mathrm{x}, \mathrm{y}, \mathrm{z}$, tu podes misturar, tu podes pegar, por isso que a gente fala "A dança dos mil e um movimentos" [risos], tem gente que fala assim, brincando, porque tu podes misturar um movimento com outro e já vira outro, e um mesmo movimento pode fazer de várias formas diferentes, com várias intenções.

Nota-se nesse enunciado que a bailarina define a dança do ventre fazendo, segundo a concepção bakhtiniana do discurso, uma citação indireta do conto $\underline{A s}$ mil e uma noites, na qual a palavra noites é trocada por movimentos. A partir daí, considerando-se a polissemia do discurso, múltiplos sentidos podem ser interpretados. Atendo-se ao que parece mais evidente, essa metáfora remete à imensa gama de possibilidades de movimentação, experimentadas pela bailarina por meio do processo criativo. Desempenha um papel fundamental nesse processo a atividade combinatória (Vygostki, 1990): a bailarina, partindo de movimentos existentes, anteriormente aprendidos, combina-os ou executa-os de um modo diferente, inventando assim um novo passo e reinventando com isso a própria técnica, ao mesmo tempo em que se constitui como sujeito criador nessa atividade.

\section{O Corpo na dança do ventre: a consciência da bailarina}

Outro tema recorrente no discurso de Jalila foi o corpo, que na dança assume o primeiro plano como consciência corporal por meio da qual o sujeito se expressa e se percebe:

A consciência corporal é tu perceber que está dentro do corpo [riso]. Perceber o teu corpo, cada milímetro dele, sentir da ponta do dedo da mão até a ponta do dedo do pé, até a ponta do fio do cabelo. Conseguir sentir a cada movimento o que é que aquele movimento desperta dentro de ti, e o que é que está acontecendo, que tipo de intenção tu estás colocando na hora que faz o movimento, por isso que eu falo de musculatura, de articulação, a diferença é simplesmente intenção né, de tu perceber os teus ossos, por exemplo, movimento de articulação, tem que perceber os teus ossos, onde é que eles estão.

Consciência corporal, para Jalila, é sentir-se por dentro, sentido visceral dos efeitos do movimento sobre o corpo: músculos, ossos e articulações. É uma consciência sensível, cinestésica, relativa ao corpo interior, termo usado por Bakhtin para falar do conjunto de sensações orgânicas, necessidades e desejos que compõem a "carne mortal da vivência" (Bakhtin, 2003a, p.105). Consoante o autor, o eu vivencia a si próprio enquanto corpo interior, constituindo-se em relação ao outro como corpo exterior. Cada movimento dançado é visto exteriormente pelo outro, mas sentido interiormente pela bailarina, na dialética entre objetivação e subjetivação que a constitui.

É a consciência corporal da bailarina que atua durante a improvisação, quando não há tempo para imaginar ou planejar mentalmente a sequência de passos da dança. Neste caso, explica Jalila: 
É todo um trabalho de consciência corporal. Agente tem que primeiro se sentir por dentro ... Aí a gente começa a deixar o corpo falar, é mais ou menos como se o corpo falasse. Claro que é tudo junto, tua emoção está no teu corpo, teu corpo está falando, está botando para fora alguma emoção também. E é isso que acontece no improviso pra mim, eu ouço a música e a música é como se fosse o que vai motivar a emoção em mim, vai me trazer mais emoção naquele momento e aí sentindo a música, percebendo o que o meu corpo está com vontade de fazer, aí a dança vai nascendo, sabe [risos].

O trabalho de consciência corporal no improviso é sensivelmente mediado pela música e pela emoção, conforme descreve a bailarina. Pode-se analisar que nesse trabalho o corpo da bailarina se constitui como espaço para uma escuta sensível da música, emotiva e ao mesmo tempo responsiva, uma vez que seu movimento nasce como resposta ao som que a afeta. Nessa relação estética, "a música provoca aquilo que chamo de emoção instintiva, ressonância, correspondências que são atraídas por semelhanças de pulsação" (Santaella, 2001, p. 83), ou seja, o corpo dançante pulsa com a música.

A bailarina deixa então o corpo falar, mas não de qualquer maneira, e sim na linguagem específica daquele gênero de dança, pois sua consciência corporal é semioticamente mediada pelos movimentos, além, é claro, de também o ser pelas sensações, emoções e pensamentos. É por meio dos passos de dança que as emoções despertadas pela música encontram expressão, através de uma catarse (Vygostki, 1999) que vai além da simples descarga motora da emoção, pois essa é transformada por meio da elaboração estética. Nessa interação com a música, o corpo da bailarina se constitui como um corpo dialógico.

\section{Corpo e música: a bailarina como maestro e personificação do som}

Através da relação estética que o sujeito estabelece com a música no processo de dançar, constitui-se um corpo musical, como se vê na seguinte descrição, em que Jalila se autoidentifica como maestro da música:

A impressão que eu tenho é como se eu fosse meio que um maestro da música, sabe: a música toca e eu vou assim fazendo a representação gráfica daquele som com o meu corpo, com o meu olhar, com a minha expressão. E eu tento traduzir a música em movimento, mas ou menos por aí mesmo, como se eu quisesse desenhar a música no espaço com meu corpo. Eu ouço aquele som, aquele som já me traz algum tipo de imagem e aí eu já traduzo ela num movimento. Às vezes nem chega a ter uma imagem, já vai direto para o corpo, sabe, varia.

A metáfora do maestro enunciada por Jalila descortina à análise uma visão da dança do ventre como discurso plurimodal, em que estão presentes diferentes linguagens: musical, verbal (se for uma canção), movimento, imagem. Todas essas linguagens, por sua vez, formam um coro de vozes regido bela bailarina-maestro. Assim como o maestro rege a orquestra através de sua movimentação corporal, por meio da qual "mostra a música" para os músicos, a bailarina, quando dança com música ao vivo, também está à frente da orquestra. Porém, no caso da dança do ventre, "mostra a música" para a plateia, ou seja, dirige-se ao público traduzindo o som em movimento por meio de seu corpo dançante.

Nessa tradução, desenvolve-se um processo de semiose que constitui a dança como pensamento do corpo (Katz, 2005). Nesse processo, o movimento é um signo gerado na relação icônica (por semelhança de formas) com outros signos (os sons, imagens, palavras cantadas, emoções), por meio da leitura musical que a bailarina realiza com seu corpo, conforme explica Jalila:

Tem essa forma da palavra que eu sei qual é, que é racional, tem a outra que é da imagem, que eu ouço aquele som e imagino alguma coisa né, vem uma imagem na minha cabeça. E a outra forma que seria talvez a mais complicada de explicar [risos]: parece que o som entra dentro de ti e te mexe, sabe, como se fosse uma mágica! Ele entra no teu corpo e o teu corpo vai conversando com aquele som, sabe, vai um diálogo, não sei se assim dá para entender. Mas a sensação é mais ou menos essa: como se o som te possuísse, sei lá, alguma coisa assim.

Podemos ver que Jalila menciona um caso especial na dança do ventre: o "corpo tomado" pelo som, quando "O ritmo penetra no corpo, cria-se uma fusão e, de repente, o próprio corpo parece ser a fonte geradora do ritmo" (Santaella, 2001, p. 83). Em certo sentido, o som realmente entra no corpo da bailarina, pois o som é uma onda mecânica que se propaga com uma determinada vibração, agitando as moléculas do ar. Essa vibração, por sua vez, ao atingir uma barreira material como o corpo humano, nele reverbera e faz com que suas moléculas também vibrem. É por isso que os surdos podem sentir a música, embora não a escutem.

Nessa estreita e intensa relação da bailarina com a música, Jalila sente que o som penetra seu corpo, que, por sua vez conversa com o som, ou seja, sendo mobilizado pela música, move-se em uníssono com ela. Nessa fusão, o corpo se movimenta imediatamente em resposta ao som, convertendo-o em realidade plástica, visual, pois "na dança as circunvoluções do corpo dão forma visível ao ritmo" (Santaella, 2001, p. 84). Nessa possessão pela música, portanto, a bailarina personifica o som, tornando-o visível para o espectador.

\section{Relações estéticas entre bailarina e espectad}

Além da música, da emoção, da técnica da bailarina, o contexto social em que ela se encontra, ou 
seja, a qualidade do espaço, o tempo e a presença da plateia constituem o modo como a dança se objetiva. A apropriação dos sentidos socialmente produzidos nessa relação estética com um outro, em um determinado tempo e espaço, constitui a própria bailarina e suas possibilidades. A importância dessa relação é recorrente no discurso de Jalila, a partir do qual se podem analisar diferentes olhares do espectador, conforme veremos nos trechos da entrevista a seguir apresentados:

O público com certeza ele influencia, aí vai depender muito de como eu vou me posicionar. Tem dias que, se o público está muito difícil, sabe, pessoas que olham pra ti só sugando, que não tem uma troca, tu não sente que vem uma energia boa ou às vezes nem vem energia nenhuma sabe. Parece que está todo mundo apático assim, ou todo mundo conversando sei lá, ninguém está nem aí, parece que tu és uma planta decorando o ambiente, não parece que tu és uma pessoa, sabe, que estás ali se expressando.

Na dança, assim como em outras artes, nem sempre o público concreto corresponde à audiência ideal a quem se dirige o artista por meio de sua obra. No relato de Jalila, a relação com o espectador é mediada por um olhar indiferente, causando à bailarina uma sensação de invisibilidade, ou seja, afetando-a como uma negação de sua presença. Ao sentir-se como uma planta decorando o ambiente, ela se defronta com um olhar em que ela não é figura, mas fundo. Nesse caso, o não reconhecimento do eu pelo outro destitui a bailarina de seu lugar de referência. Outra situação em que não se constrói uma relação estética do tipo sujeito-sujeito, mas sim uma relação sujeito-objeto entre espectador e bailarina, é assim descrita por Jalila:

Às vezes tem algumas pessoas que tão olhando, geralmente público masculino, às vezes está olhando e está assim só viajando, não está olhando a dança. Tu se sente mal né, porque se sente meio sugada pela pessoa, não tem uma troca, a pessoa parece que só está se aproveitando do teu corpo ali se mexendo, do visual do teu corpo, mas ela não está reverenciando, ela não está realmente admirando a dança, ela está aproveitando como se fosse uma imagem na televisão, sabe, mas como se não tivesse uma pessoa ali dançando.

Para o espectador, tanto homem como mulher, a visão do corpo que dança coloca em questão seu próprio corpo, ainda que se presuma de um modo diferente em função do gênero, podendo ser percebido como signo de identidade ou desejo (Hanna, 1999). Nessa percepção, "O movimento do outro coloca em jogo a experiência do movimento do próprio observador: a informação visual gera, no espectador, uma experiência cinestésica imediata" (Dantas, 1999, p. 116). Os efeitos dessa experiência podem ser diversos, a depender tanto da postura da bailarina em cena quanto da intenção do público. Na situação descrita, fica clara a posição do espectador, cujo olhar percebe a bailarina como objeto de desejo. Nesse caso, Jalila sente que o espectador não está de fato admirando a dança. Pode-se analisar que, mediada por este olhar objetificante, não há contemplação estética por parte do espectador, já que, segundo Bakhtin (2003a), o enfoque sexual é incompatível com a visão estética.

A bailarina, por sua vez, se sente despersonalizada, se sente mal, "sugada", como afirma Jalila, pois não há troca com o espectador. A troca pressupõe que a bailarina ofereça sua dança ao outro que, em contrapartida, a admira e reverencia. Pode-se compreender a troca como metáfora da relação estética, na qual o contemplador não é passivo, ou seja, ele não apenas recebe a dança, mas deve completá-la, reconhecendo seu valor estético (Bakhtin, 2003a). Esse outro modo de relação aparece, por exemplo, na seguinte fala de Jalila:

E tem também as pessoas, por exemplo, tanto homens como mulheres que olham admirando mesmo, a pessoa parece que ela está dançando junto contigo, sabe, é muito bom! Tu estás dançando assim e às vezes até acontece da pessoa mexer junto contigo sem ela perceber, ela vai, né [risos] ou com o olhar, ou com o sorriso.

Pode-se, com esse enunciado, analisar que por meio de um olhar contemplativo o sujeito se constitui como coparticipante ativo no acontecimento estético da dança, interagindo com a bailarina por meio do olhar, do sorriso, de pequenos movimentos. A dança se concretiza assim no diálogo entre bailarina e público, como possibilidade de subjetivação estética em que o eu é na presença do outro, a partir do mútuo reconhecimento, da reciprocidade, como podemos ver na continuação da fala de Jalila:

Ah, aí é muito bom! Aí parece que todo mundo está dançando junto comigo, mesmo que as pessoas estejam sentadas, e elas mesmo também sentem isso, às vezes eu percebo que elas tão se mexendo e a sensação que dá é de uma ligação assim, como se todo mundo estivesse ligado, como se eu não estivesse separada das pessoas que tão me assistindo, por isso que eu falo 'todo mundo dançando junto', é só eu dançando, mas parece que está todo mundo dançando junto por eu me sentir conectada com todo mundo.

Destaca-se, nesse enunciado, a conexão entre bailarina e contemplador, por meio da qual a dança do ventre se concretiza não apenas como uma dança para o outro, mas como uma dança com o outro. Nesse modo de relação ocorre a autoobjetivação lírica da bailarina, que se expressa na dança, compreendendo lírica como "uma visão e uma audição de mim mesmo pelos olhos emocionais e na voz emocional do outro: eu me escuto no outro, com os outros e para os outros" (Bakhtin, 2003a, p. 156). O espectador, por seu turno, constitui- 
se como partícipe da dança, à medida que a covivencia através da empatia durante sua recepção estética.

\section{Dança do ventre: uma dança dialógica}

Jalila narra a seguir uma apresentação que marcou sua trajetória:

Uma vez eu dancei em um lugar, a música era cantada, tinha uma mulher árabe cantando, e uma menina fez como se fosse meio que a cantora, ela fez um rosto assim, meio que junto comigo, foi muito legal! [risos]. Foi muito legal a sensação, eu senti que realmente tinha uma troca: eu estava dando a minha energia para ela e ela também estava passando a energia dela para mim.

Nesse enunciado fica clara a natureza comunicativa e dialógica da dança do ventre, concebida não como um monólogo da bailarina, simplesmente apresentado ao público, mas um diálogo construído na interação concreta entre ambos. Na situação relatada por Jalila, uma menina entrou em cena interpretando a cantora cuja canção a bailarina dançava e, passando a interagir com Jalila, constituiu-se como cocriadora da dança. Para a bailarina, por sua vez, a participação da pequena espectadora ensejou uma vivência gratificante, na qual sentiu uma troca de energia com ela. Essa troca baseia-se na empatia, de modo que a singularidade de cada uma foi enriquecida na intersubjetividade dessa dança dialógica.

\section{A sagrada dança do ventre}

Além da relação com as pessoas da plateia, emerge no discurso de Jalila uma forma especial de relação com um outro indizível e transcendente, quando fala sobre como se sente durante a dança:

Talvez inteira e ao mesmo tempo conectada com um todo que eu não sei explicar exatamente o que é e como é, talvez num sentido energético, como se eu tivesse totalmente consciente e inconsciente ao mesmo tempo [riso], mas é uma sensação de talvez plenitude seria a palavra. Essencialmente assim é um prazer muito grande. E aí a emoção vai variando, dependendo da música, dependendo do momento, mas o prazer acho que é o que mais acontece e uma sensação de que tu estás viva, eu não sei explicar direito, mas é uma hora que você vibra, está vibrando! [risos]. É uma coisa bem intensa, de estar de bem com tudo. Tu ficas totalmente inteira.

A conexão com um todo inexplicável, o aspecto energético dessa relação, a presença de um estado alterado de consciência e as sensações de plenitude, prazer e intensidade vital relatadas pela bailarina são sentidos que podem estar presentes em algumas experiências místicas. No Sama, por exemplo, ritual em que os derviches - membros da corrente mística do Islã - realizam uma dança giratória, o estado de êxtase do dançarino prepara o corpo para a entrada de Deus (Camargo, 1997). Essa conexão, segundo explica a antropóloga, é uma forma especial de união mística, baseada na "identificação' com a divindade", a partir da possessão pela baraka, energia divina (Camargo, 1997, p. 134).

Claro que o contexto em que a dança do ventre acontece protagonizada por Jalila é consideravelmente diverso daquele. Entretanto, lembrando que em outro momento de seu discurso Jalila revela a expectativa de ser reverenciada pelo espectador e que um dos significados de reverenciar é "prestar culto a", é possível cogitar que talvez a dança do ventre possibilite à bailarina, de algum modo, divinizar-se. Essa interpretação leva em conta também outro momento da entrevista, em que Jalila afirma:

Quando se vê uma bailarina dançando com uma criança, traz uma pureza maior assim para essa dança, mostra para as pessoas que a dança ela não é uma dança simplesmente de sedução da mulher com o homem, não. É uma dança da vida! Dança de celebrar a vida, celebrar ser mulher, celebrar o poder de gerar um filho! E acho que por isso também quando dança com criança é tão legal, porque puxa esse lado da Grande Mãe.

A Grande Mãe é a mãe em sentido mitológico, a deusa em cujo útero o universo teria sido gerado, e remete ao aspecto sagrado presente nas longínquas origens da dança do ventre (Suméria, 4500 a.C.), quando se acreditava que essa fazia parte de cultos a deusas da fertilidade (Bencardini, 2002). É a esse sentido histórico que Jalila remete-se em seu discurso, posicionando-se contrária à interpretação preconceituosa da dança do ventre como uma dança afrodisíaca - função associada ao período em que era realizada nos haréns (Turquia, século XV). Ao trazer à tona esse sentido, de certa forma Jalila reafirma o lugar simbólico que ocupa como bailarina e no qual deseja ser reconhecida enquanto dança, lugar em que a sexualidade feminina é resgatada como manifestação da divindade pelo seu poder de gerar a vida. Vemos aí, portanto, a possibilidade de uma vivência extática, associada ao sagrado, através da objetivação artística da personagem divina pela bailarina.

\section{Constituir-se feminina na/com a dança do ventre}

A dança do ventre é uma atividade em que se estabelece uma relação estética com o feminino, categoria central à análise a partir da definição apresentada pela entrevistada:

A dança do ventre para mim é a dança da mulher, sabe, a dança do feminino. É uma dança assim que a gente se expressa o máximo na nossa essência feminina. É um momento que tu podes flutuar, que tu podes voar. Eu brinco com as alunas: 'voa'. Tu podes voar, mas ao mesmo tempo tu podes às vezes ser mais firme. Tu 
podes estar trabalhando vários aspectos do feminino, sabe, o aspecto mais firme, mais forte, o aspecto mais suave, né, o aspecto mais lúdico, mais de brincadeira, o sensual, né, o lado sensual.

Para Jalila, a dança do ventre é a expressão do feminino, sendo esse seu significado mais geral e perene - ainda que, em uma perspectiva histórico-cultural, não possamos esquecer que a atividade é ressignificada de diferentes modos em função dos diversos contextos sociais em que essa dança foi e é realizada. Outro aspecto a ser analisado é que, embora fale em essência feminina, a seguir a bailarina associa a dança a um modo de trabalhar aspectos do feminino. O feminino, portanto, se constitui aí não como um dado a priori, mas como mote geral para o trabalho de enformação estética da dança do ventre, do qual resultam diferentes modos possíveis de se constituir feminina (forte, suave, lúdica, sensual). Nesse sentido, a dança do ventre objetiva também como o aprendizado de um certo modo de ser feminino, pois somente depois de incorporar determinados movimentos e posturas cênicas é que o sujeito poderá, dançando, expressá-lo "naturalmente". Em síntese, na objetivação artística do sujeito na dança do ventre, o feminino é esteticamente (re)criado.

\section{Considerações finais}

Diante da complexidade do objeto desta pesquisa, não é possível estabelecer uma conclusão definitiva. Como um objeto em movimento, a dança do ventre mobiliza-nos a acompanhá-la em suas circunvoluções, conduzindo-nos a uma compreensão polissêmica. Não há, por isso, uma resposta única para a problemática da pesquisa, porque todas as relações analisadas - e possivelmente outras que não foram incluídas no recorte deste estudo - interagem de um modo dinâmico e único em cada dança do ventre realizada. Dinâmica das múltiplas relações estéticas cujo jogo de forças forja a dança como seu amálgama.

De acordo com a análise realizada, a constituição do sujeito na dança do ventre é mediada pelas diversas relações estéticas por cujo intermédio essa atividade se concretiza. A relação estética com o corpo generificado revelou-se como fundamental, possibilitando a compreensão da dança do ventre como produção estética do feminino, ou seja, como um modo de objetivação e subjetivação que, pela forma como constrói esteticamente o corpo da bailarina, inscreve nele as marcas de um lugar socialmente reconhecido como feminino.

Outro ponto importante a ser considerado diz respeito ao processo de constituição do sujeito na dança do ventre via relações estéticas com diferentes outros. Assim, na relação com a música, a bailarina se cons- titui como personificação do som; na relação com um outro sagrado, representa uma personagem divina; e na relação com o público, pode se constituir de diferentes modos conforme os diferentes olhares dos espectadores. Destaca-se, aí, a condição dialógica da dança do ventre, criada na interação concreta da bailarina com esses muitos outros com quem e para quem dança.

A dança do ventre, portanto, mais do que apresentar um produto estético, constitui-se como "um processo em que um sujeito se esteticiza" (Reis, 2007, p. 57). Torna-se difícil nessa atividade a separação entre arte e vida, pois, perante o olhar que ratifica seu valor estético, a bailarina se transforma em obra viva. Com isso, este estudo descortina à Psicologia Social uma compreensão do sujeito relacional dessa atividade como devir estético e convida outros pesquisadores a investigarem as especificidades do processo de constituição do sujeito mediado por essa e outras formas de arte.

\section{Notas}

1 Essa dimensão histórica e cultural da dança do ventre foi apresentada e discutida amplamente na dissertação, porém, devido às limitações deste artigo, são aqui somente anunciadas. Recomenda-se ao leitor interessado que acesse a versão integral da pesquisa, disponível em www.cfh.ufsc.br/ ppgp

2 Esse desdobramento do sujeito provavelmente acontece em outras atividades artístico-criadoras, porém essa discussão foge ao escopo deste trabalho.

\section{Referências}

Bakhtin, M. M. (1993). Toward a Philosophy of the Act (V. Liapunov, trad.). Austin, TX: University of Texas Press.

Bakhtin, M. M. (2003a). O autor e a personagem na atividade estética. In M.M Bakhtin, Estética da criação verbal (pp. 3-192). São Paulo: Martins Fontes.

Bakhtin, M. M. (2003b). Metodologia das Ciências Humanas. In M.M Bakhtin, Estética da criação verbal (pp. 393-410). São Paulo: Martins Fontes.

Bakhtin, M. M. (2004). Marxismo e filosofia da linguagem. São Paulo: Hucitec.

Bencardini, P. (2002). Dança do ventre: ciência e arte. São Paulo: Textonovo.

Bezerra, P. (2005). Polifonia. In B. Brait (Org.), Bakhtin, conceitos-chave (pp.191-200). São Paulo: Contexto.

Butler, J. (2003). Problemas de gênero: feminismo e subversão da identidade. Rio de Janeiro: Civilização Brasileira.

Camargo, G. G. A. (1997). Entre o camelo e o leão: a dialética do giro derviche. Uma etnografia do Sama - a dança girante dos derviches da Ordem Sufi Mevlevi. Dissertação de Mestrado, Programa de Pós-graduação em História, Universidade Federal de Santa Catarina, Florianópolis, SC.

Dantas, M. (1999). Dança: o enigma do movimento. Porto Alegre: Editora UFRGS.

De Lauretis, T. (2003, dezembro). Imagenação. Caderno de Pesquisa e Debate do Núcleo de Estudos de Gênero/UFPR: Representações de Gênero no Cinema, 2, 1-79. 
Hanna, J. L. (1999). Dança, sexo e gênero: signos de identidade, dominação, desafio e desejo. Rio de Janeiro: Rocco.

Katz, H. T. (2005). Um, dois, três. A dança é o pensamento do corpo. Belo Horizonte: Helena Katz.

Nicholson, L. (2000). Interpretando Gênero. Revista Estudos Feministas, 8(2), 9-41.

Peixoto, C. E. (1998). Caleidoscópio de imagens: o uso do vídeo e a sua contribuição à análise das relações sociais. In B. F. Bianco \& M. L. M. Leite (Orgs.), Desafios da imagem: Fotografia, iconografia e vídeo nas ciências sociais (pp. 213-224). Campinas, SP: Papirus.

Reis, A. C. (2007). A atividade estética da dança do ventre. Dissertação de Mestrado, Programa de Pós-Graduação em Psicologia, Universidade Federal de Santa Catarina, Florianópolis, SC.

Sánchez-Vázquez, A. (1999). Convite à Estética. Rio de Janeiro: Civilização Brasileira.

Santaella, L. (2001). Matrizes da linguagem e pensamento sonora, visual, verbal. São Paulo: Iluminuras.

Scott, J. (1990). Gênero, uma categoria útil de análise histórica. Revista Educação e Sociedade, 16(2), 5-22.

Sobral, A. (2005). Ato, atividade e evento. In B. Brait (Org.), Bakhtin: conceitos-chave (pp. 11-36). São Paulo: Contexto.

Spink, P. (2000). Análise de Documentos de Domínio Público. In M. J. Spink (Org.), Práticas discursivas e produção de sentidos no cotidiano; aproximações teóricas e metodológicas (pp. 123-151). São Paulo: Cortez.

Szymanski, H. (2000). Entrevista reflexiva: um olhar psicológico para a entrevista em pesquisa. Psicologia da Educação: Revista do Programa de Estudos Pós-Graduados em Psicologia da Educação da PUC-SP, 10/11, 193-215.

Vygotski, L. S. (1990). La imaginacion y el arte em la infância. Madri: Akal.
Vygotski, L. S. (1991). Obras Escogidas II: problemas de psicología general. Madrid: Visor Distribuiciones.

Vygotski, L. S. (1999). Psicologia da Arte. São Paulo: Martins Fontes.

Recebido em: 29/07/2008

Revisão em: 03/04/2009

Aceite final em: 27/08/2009

Alice Casanova dos Reis é Mestre em Psicologia pela Universidade Federal de Santa Catarina (UFSC) e Doutoranda pelo Programa de Pós-Graduação em Psicologia da Universidade de São Paulo (USP). Endereço:

Av. Engenheiro Max de Souza, 1178, apto 502 A. Florianópolis/SC. CEP 88080-000. E-mail: alicecasanova@yahoo.com.br

Andréa Vieira Zanella é Professora do Departamento de Psicologia e do Programa de Pós-Graduação em Psicologia da Universidade Federal de Santa Catarina, Brasil e bolsista em produtividade do CNPq. E-mail: $\underline{\text { azanella@cfh.ufsc.br }}$

\section{Como citar:}

Reis, A. C. \& Zanella, A. V. (2010). A constituição do sujeito na atividade estética da dança do ventre. Psicologia \& Sociedade, 22(1), 149-156. 